\title{
The Song Cycle: Hermeneutic and Communication Approaches
}

\author{
Elena Borisova \\ The Gnesins Russian Academy of Music \\ Moscow, Russia \\ E-mail: t202@mail.ru
}

\author{
Elena Klimenko \\ The Russian State Specialized Academy of Arts \\ Moscow, Russia \\ E-mail: klimenko.ev@gmail.com
}

\begin{abstract}
The paper is dedicated to interpretation-based multifaceted connections characteristic to the song cycle genre. The authors discuss the song cycle evolution, the ways of its transformation development trends. Being one of the beloved genres of the classical music, it has undergone dramatic changes which stem from globalization, social and cultural transformations, and changes in people's mindset. The song cycle here is viewed as a multifaceted system, its elements building a hermeneutic bridge between language, music, communication, mind and emotions. The genre is unique in view of its being an organic unity of poetry and music, as well as a mediator between poetic and musical meaning, interpretatively linking the poet, composer, performer and listener outside of space and time.
\end{abstract}

Keywords-song cycle; genre; poetry; music; narrative; history and modernity; hermeneutics; communication; imagination; picture; listener; performer; action on the spot

\section{INTRODUCTION}

The song cycle belongs to the most popular genres of classical music. There are so many song cycles written by Russian and foreign composers over the last two centuries that its full list can hardly be made. As a beginner, a composer has to learn vocal composition and create a set of chamber miniatures. At the same time, almost every great master had left at least one book of such masterpieces. The majority of European schools of composition involved the genre of the song cycle, which often made distinctiveness of traditional music come in the full force. Austrian-German tradition became famous with Shubert and Schumann, Brahms and Wolf, Hindemith and R. Strauss. Among French "melody" creators are Berlioz, Massenet, Fauré, Debussy, Ravel. We can hardly imagine the Russian history of music without vocal cycles of Glinka, Mussorgsky, RimskyKorsakov, Tchaikovsky, Prokofiev, Shostakovich, Sviridov, Gavrilin and many others.

Song cycles tend to open new stylistic trends in music. It is a well-known fact that Schubert's "Die Schöne Müllerin" ("The Miller's Beautiful Daughter") and "Winterreise" ("Winter Journey") launched the Romantic Age in music. But "Pierrot lunaire" ("Moonstruck Pierrot") by Schoenberg, as well as "Le Marteau sans maître" ("The Hammer without a Master") by Boulez, being milestones in the history of the first and second avant-guarde of the 20th century, should also be classified as the genre of chamber vocal miniature.

However, there are some "blank spots" in this notable genre. It is sometimes difficult to mark a dividing line between a song cycle and a number of several vocal miniatures having no unity, but one time basis only. When we deal with the period of the 19th-century genre's dawn and development, the question of authentic terminology comes up. Works, traditionally called song cycles today, may not have been called that way when being created. German Liederkreis, Liederkranz, Liederzyklus, etc, rendered into Russian as "цикл песен" (song cycle) could have had another meaning at the time when they were current.

Besides, the time has come to study its multidimensional context-based discourse, its radiating elements being music, language, communication, history, psychology and even philosophy, and come closer to answering why for almost 200 years song cycles have bewitched so many musicians and audiences, inspiring countless performances.

\section{THE RUSSIAN MUSICOLOGY ON THE SONG CYCLE GENRE}

In Russia there exists vast literature on musicology dedicated to the theory of the song cycle as a music genre and to some composers creating music in its framework. V.A. Vasina-Grossman's treatises are the first to mention. Among advantages of a song cycle over a separate song or romance the researcher notes a possibility to fully reflect a wide range of true-life things, to present "selected by a composer type of reflection of poetic images" - not fragmentarily, but as a whole. In the "suite-like" context it may mean "a sharp opposition of contrasting musical and poetic images, which is impossible within the bounds of romance" [1].

The idea of suite-based principle of constructing vocal cycle given by Vasina-Grossman, was developed in J.V. Sokolov's monography "Morphological System of Music and Its Artistic Genres". The treatise specifies the genre as "variable determined", embracing "various pieces from cohesive narrative compositions to a group of romances only connected by the similar mood". The author points out two types of grouping vocal miniatures as a cyclic wholeness based on genre stylistics (M. Mussorgsky's romances and "Songs with Lyrics written by R. Burns and Translated by S. 
Marshak" by G. Sviridov given as examples. E.K.) and musical dramaturgy, the latter being divided into two more groups - with narrative (there are numerous well-known examples) and without it, such as "Immortelle" by S. Taneyev [2].

Significant notes on the difference between a vocal cycle and a book of songs were made by $\mathrm{T}$. Kuryshova through the examples of Soviet composers' works (they refer mainly to the second type according to O. Sokolov's classification, being based on musical dramaturgy. E.K.). Among the key criteria cyclic composition "in the full sense of the word" the researcher lists "an irremissible for the cycle inner "hidden" idea, logical development of images from song to song and the integrity of the contexts of dramaturgy and composition, which also manifests itself as a certain development of melody and harmony" [3]. The idea of dramaturgical wholeness was developed further in A. Krylova's methodical work, where the cycle was considered as "more than just a musical phenomenon" and the importance of a poetic unity of the text meaningfully chosen by a composer was stressed [4].

There are many significant theoretical states in Russian musicology about the vocal cycle genre, including those appeared due to the 19th-20th centuries composers. However, there is no final answer what the vocal cycle is and if there exist any precise limits of the genre. The research, which has been conducted recently in the post-Soviet countries are symptomatic, though not always successful. For example, a Ukrainian investigator finalizes his work with a thorough but cumbersome and impractical definition: "Vocal cycle is a narrative-like musical-poetic composition, the type of which depends on the character of connection with a poetic subject and is implemented in space-time continuum of a literary text created by it, embracing all the characteristics of cycle building - from architypes of ontological cyclization to specific means of its embodiment in the technical language of music" [5]. Yu. Radkevitch analyses the concept of the vocal cycle on the basis of the meaning of the word "cycle", given by "The Modern Dictionary of Foreign Words", published in Moscow. Still, her definition is not comprehensive either, as it also lacks the precise limits of genre. She says, "The vocal cycle is a special kind of work based on the combination of music and poetry, which has a distinctive lyrical character and belongs to the genre of chamber music only" [6].

Besides the above works, directly referred to the theme of this article, we need to note the ones of some Russian music historians, i.e. reviews, articles and studies, dedicated to certain cycles, the sections of the educational book in 3 volumes "Music of Austria and Germany in the 19th Century", and the series "The History of Russian Music in 10 Volumes", being published by the State Institute of Art Criticism; sections of monograph by L. Kirillina "Beethoven: Life and Work", dedicated to the song cycle "An die ferne Geliebte" ("To the Distant Beloved") Yu. Khokhlov's study "Die Schöne Müllerin by F. Shubert" and his other works; the well-known article of P. Wolfius, devoted to the same song cycle; N. Pilipenko's dissertation and article on the interpretation of poetical characters and musical images of
"Die Schöne Müllerin", as well as the study of E. Durandina "The Vocal Works of Mussorgsky".

\section{The WeSt-European Musicology ON THE SONG CYCLE GENRE}

The above genre was extensively covered by foreign scientists, who gathered, presented and analyzed the rich historiographical sources. Here are some major western editions presenting the modern vision of the song cycle. First of all, it's a special edition of "Cambridge Introductions into Music" by Laura Tunbridge [7]. The book being scientific, it concisely and clearly tells the reader the history of the genre from Beethoven's "An die ferne Geliebte" to nowadays. She touches performing practices in different historical periods, development of the theory of the genre, the national peculiarities of its interpretation, the genuine song cycle in modern mass culture. The author discusses positions of contemporary western researchers on the most arguable points, reviews a wide range of scientific literature and suggests books for further studying. The book starts with a valuable list of the most considerable works in the history of the song cycle, presented in chronical order. Tunbridge avoids extreme viewpoints of western researchers on if the romantic song cycle is organic wholeness or tends to be fragmentary (Barbara Turchin and David Ferris being on the opposite sides of the heated discussion). She also shares a simple and reasonable idea: "Although there are many song cycles that nicely illustrate the "musically composed" model, there are many more that are arranged more loosely, by topic or simply by poet: the different types have continued side by side, and all can be referred to as cycles. To put this another way: it will become apparent during the course of this book that the idea of the song cycle has often been more important than whether the cycle itself is a coherent, cyclical structure" [7]. It should be noted, that the author writes about the composer's idea of the song cycle, his conscious efforts to unite pieces by their meaningful aspects, rather than about conceptual musical wholeness of the vocal cycle (the subject widely covered by Russian and foreign researches).

The modern vision of the genre was extensively influenced by John Daverio's essay on the history of German romantic song cycle, published in 2010 (revised and with an Afterword by David Ferris), though written at the end of the 19th century. The achievement of Daverio is not only innovative, bright and laconic characteristics of several classical masterpieces of Beethoven, Shubert, Schuman, Wolf, Brahms, anticipating the conception of fragmentarity of the song cycle, which was given by him later. He was the first to highly appreciate the significance for study and understanding the genre such aspects as the history of performing practice and that of the term of song cycle (more exactly, the whole group of German names of the genre, which can be rendered in such way with certain assumptions).

At the beginning of the $21 \mathrm{st}$ century that approach became widespread and was developed in the dissertation of Ruth O. Bingham "The song cycle in German-speaking countries 1790-1840: approaches to a changing genre", as well as in her essay "The Early Nineteenth-Century Song Cycle" in "The Cambridge Companion to the Lied" [8]. Not 
only did she manage to clarify the diversity of German names of the genre in the time when the history of the song cycle just began, but also suggested a convincing systematization of the 19th-century collections of songs applicable both to the pieces of the beginning of the century and to those highly artistic works, which are acknowledged as masterpieces of the genre today. At the same time the dissertation of Luise E. Peake "The song cycle: a preliminary inquiry into the beginnings of the romantic song cycle, and the nature of an art form" and, especially, in her work "The Antecedents of Beethoven's Liederkreis" there are many considerable observations and ideas, which haven't yet been developed [9]. Although, perhaps, not all Peake's interpretations are to be accepted without reservation, her works are the ones, which set the right way towards studying the further history of the song cycle.

Investigations on the connection of the first song cycles (of Beethoven and Shubert) with German vocal collections of the end of the 17th century - the first decades of the 19th century, followed after Peake's ones, revealed an intersection of several aesthetic paradigms. Connections between "An die ferne Geliebte", "Die Schöne Müllerin", "Winterreise" and literary and musical Romanticism are evident - they are traditionally discussed in modern studies. However those collections of songs have a rational, graphic sequence "music for eyes", which implies that its audience would get involved in decoding an ingenious idea of the author. Such collections were typical for the Baroque music, the 1st, 2nd and $3 \mathrm{~d}$ movements of J.S. Bach's "Clavier Exercises" being one of the most well-known examples. Due to printed works popular at the beginning of the 19th century as Liederkreis, etc., that early practice morphed into entertainment. In contrast to the Russian song cycle, Liederkreis existed as the wholeness because it could be treated as a book, or, at least, a note-book to understand the idea of the creator of the cycle (kreis) in another dimension, rather than because it was performed in succession to the very end (though sometimes it could be so).

The decisive factor which had influenced the modern view on the song cycle (with fixed genre term) was extensive musical practice. As the artistic level of the German Lied (as well as Russian romance) was increasing, professional performance of collections of songs gradually became the norm. Here we should remember Laura Tunbridge's words about the importance of the idea for the song cycle. We certainly agree with it, but it is worth noting that the idea of the song cycle emerges from the composer's representation of a concert performance of the series of lyrical vocal miniatures being created - in the whole and in a certain order considered by him. It is a concert performance that makes a set of vocal songs a song cycle. This idea seems to be evident today, but the 19th-century music practice went towards it gradually, as to perform the collection of songs from the beginning to the end was not so common at that time, in contrast to symphonies, piano concerts, quartets and other instrumental cyclic forms.

\section{ThE SONG CYClE GENRE IN THE CONTEXT OF HERMENEUTICS AND COMMUNICATION}

If we view the song cycle genre in the context of hermeneutics and communication, it can be regarded as a multifaceted system, which encompasses heterogeneous elements, such as text/discourse, music, language, mind, emotions, historical, cultural and psychological background, involving the issues of interpretation. In a song cycle the singer "faces the ultimate challenge: to sustain an audience interest by communicating drama, emotion, mood, and stories... During the course of the evening the singer must play myriads roles and transmit numerous emotions and states of mind. The singer becomes a storyteller par excellence: the link between the composer, the poet, and the listener" [10]. The singer needs to fit together harmoniously all cycle parts as the complete entity to make the audience trace a coherent narrative line, as if both - the singer and the audience - are doing a puzzle. A "unique hybrid of poetry and music, sharing similar characteristics, such as rhythmic patterns, accents, tempo variations, melodic phrases (song), pitch inflection (speech)" (C. Kimball), the song cycle is able to heighten images, music facilitating words by color, nuance, and shape channeled by the singer to the listener.

"Optimum communication of musical and poetic imagery requires solid vocal technique, good diction and language skills, musicianship, a sense of drama, and an inquiring mind", writes Carol Kimball in her book "Art Song: Linking Poetry and Music". "The performance of a musical work with the performer adding his musical understanding, experience, and personality to the composer's musical score. It is an artistic merger in which the performer seeks to communicate his ideas about a piece of music, forged through studying and assimilating music, poem, and characterization [10].

An interpretative act, the most essential element of the hermeneutics and communication system, should be personalized rather than stereotyped (with regard to both the performer and the listener), otherwise "imagination would count for nothing and originality would be a dead letter" and the singer would perform the song cycle wonderfully, but one-dimensionally. "The singer needs to build an internal world filled with the information they have researched about the poem and music, practiced technically and finally - let that world be reflected out to their listening audience" [10].

"The generic form of the song cycle is essentially literary but the medium of composition and performance is essentially musical... It demands competence for the reception and interpretation by an audience, not only a singer and accompanist: sometimes the plot is not discernable but the entire work may be considered as "monodrama" [11]. A dynamic unity of meaning is inspired by the consciousness of the performer and listener, who should seek not only to receive but also to perceive, the text-music message, which means making the process cognitive, axiological, emotionrelated. In the words of Cyrus Hamlin, "The winter journey is, our own, as we hear and respond to the performance of the cycle" [11]. The mental picture (image) formation leads to emotional response. That is why the meaning of songs 
being performed should be conveyed to the listener without any distortion. But a foreign language can be a barrier to the singer and the listener alike. So, must we always hear the song cycles "properly" - in the language as convention dictates (i.e. Shubert in German, etc.)? Or, can we do a translation, which helps introduce song cycles to a wider international audience? The Guardian article "From Schubert to Sinatra: Why the Song Cycle Speaks to the Heart" by Christopher Fox says, that one of the problems having often been faced by singers of the song cycle genre is how to communicate it: “... If your listeners don't understand the language, how can you share the meaning of the words? You might print them on a screen or in a programme book, but then you lose part of your audience's attention. Or you might sing a version of the music in which the words have been translated. This used to be the way it was done in England. Foreign music, whether Bach cantatas, Mozart operas or Schubert songs, was sung to words that the locals could understand" [12]. The author marks that there was a time where "the importance of communicating directly and clearly with your audience was more important for a singer than the notion of being absolutely faithful to the original version of a work" and tells the readers about the pianist Christopher Glinn, who commissioned a new translation of "Die Schöne Müllerin" from Jeremy Sams ("The Beautiful Maid of the Mill" instead of widespread "The Miller's Beautiful Daughter"): "Sams' translations are freer than any of their predecessors. Rather than making a word for word substitution, he has created a new poetry that matches idiomatic English to the sense of Müller's words and the rhythms of Schubert's music" [12].

It is the singer's and the listener's capacity to "hear the images" that makes a performance rich in communication and helps hear not poetry set to music but a song cycle as the integrity. A dramatic text and music interaction generates a natural melding of story and music, poetry and a musical setting making the singer's and the audience's images double potent and the mental picture (image) formation leading to emotional response and understanding.

\section{CONCLUSION}

Today any song collection, which was performed on the stage or became a recorded album, can be called a "cycle". It does not mean that there is no order in a performing practice. Performance of the whole cycle itself is one of the achievements of the 21 st-century culture. The idea of making listeners perceive diverse vocal pieces as internally connected cycles belongs to their creators - composers of those times, who sought to inner unity of their works, at least, by being "regisseurs" of poetic texts (according to A. Krylova's apt turn of phrase. E.K.) Song cycles were not mentioned in study books on musical form, their authors, however, being creators of quite canonic sonata and symphonic cycles, symphonic and piano poems and other forms of instrumental music, intending the inner coherence of autonomous parts the wholeness was consisted of. Deliberately or not, this romantic aesthetics of the "organic" unity of a musical work was introduced into their collections of romances and songs. The degree of inner unity of such works, as well as that of the author's deliberation, differed much. There is a distance between M. Glinka's "A Farewell to Saint Petersburg", M. Mussorgsky's "Child's Song" and "Six Romances" by any other Russian composer (for example, P.I. Tchaikovsky), which should be considered as a "variable determinacy" of the genre (the term by O. Sokolov. E.K.).

Thus, it is hardly possible to specify when exactly the song cycle emerged. However, the given interpretation of the genre's formation confirms a widespread opinion that Robert Schumann made a landmark contribution to it. We consider it as dual. On the one hand, in his cycles the composers seeks to unite several miniatures by pure musical means (textural connections between the pieces, tonal plans, piano introductions and postludes, acquiring a separate meaning), its traditionally being the focus of researchers' attention. On the other hand, not less important was the composer's aspiration to make his cycles sharply contrasted, add ambiguity and fragmentary to some numbers (as in his piano cycles) in accordance with the aesthetics of those days. Besides, such a manner stressed the hermeneutic and communication aspects of his works, bringing to the fore aural perception as the key way to understand an artistic wholeness. In case of Schumann's works the notion of Liederkreis could be viewed in a new sense, though the change was not quite realized by his contemporaries and, perhaps, by the composer himself.

A long aesthetic reflection and extensive performing practice could turn song cycle creation into a writing routine for composers. In present days, song cycles readily integrate into modern pop, jazz, folk and rock cultures in different ways, for example, due to the appearance of the concept album. "A concept album possesses all the defining characteristics of a song cycle but expresses them in more modern language: three or more defined sections that use text painting and a logical sequence of tonicities to express a single poetic theme. There are two big differences between concept albums and song cycles, however. First, concept albums often have more than one vocalist or narrator in a song. Second, concept albums are primarily a recorded musical form, while song cycles can be performed live or recorded" [13].

A modern American song cycle "Cycles of My Being" is a case in point: Mr. Brownlee, an international bel canto operatic star did a song cycle exploring black man's life. It is a 40-minute work in six parts created in collaboration with the composer Tyshawn Sorey and the poet Terrance Hayes. "The volatile music suggests the unpredictable ways racial prejudice manifests itself in daily life... The music of "Cycles of My Being" reflects both the changeability and the gravity of that life, and puts an emphasis on empathy, even from the musicians. Mr. Sorey asks all the players to read from the full score, instead of from individual parts. "I want them to see the actual lyrics," he said. "I want all of the players to have a total experience of what it means to sing the music. Imagining themselves as the vocalist, and them singing the music. That's how I like to try to frame it." [14]. 
Today we live in the world where everything is expected to be entertaining and visualized, people dealing with pictures rather than words. "We are used to pushing a button, tapping a screen, moving a mouse, and seeing a picture. The advent of YouTube allows us to watch singers, and often not listen to them" [15]. However, it seems a disputable question whether pictures can speak louder than words in the case of the song cycle. To be comprehensively understood the cycle should involve face-to-face the intelligent listener, his being able to create a semantically colorful mental picture, the visual ones (artists' stage behavior, clothes, props, art installations, etc.) playing a supportive role. It is interpretation-based composer-performer and performerlistener connection through the poetry/music discourse that creates spontaneously a microcosmic drama outside of space and time. Whether in a Medieval banquet hall, a 19thcentury salon, or a present-day venue, be it a hall, an openair stage or a classroom, the song cycle has always assimilated and will continue to assimilate to remain one of the most essential form of musical expression and powerful means of communication.

\section{REFERENCES}

[1] V. A. Vasina-Grossman, Romance Song, Muzikalnaya Entsiklopediya: 6 volumes. Moscow, 1978

[2] O. V. Sokolov, The Morphological System of Music and Its Artistic Genres: Monograph. Nizhny Novgorod: Publishing House of Nizhny Novgorod University, 1994, 218 p.

[3] T. A. Kurysheva, Chamber Vocal Cycle in Contemporary Russian Music // Questions of Musical Form. R 1. M.: Music, 1966, pp. 278313

[4] A. Krylova, The Vocal Cycle. Questions of the Theory and History of the Genre: [Lecture on Analysis of Musical Works. 17.00.02 Musicology]. M.: Gnesins Academy, 1988, 48 p.

[5] N. O. Govoruchina, Development of the Vocal Cycle and Characteristics of Its Creation (on the example of works by R. Schumann, G. Wolf, A. Schenberg): Kharkiv, 2009, 18 p.

[6] Yu. Radkevich, The Vocal Cycle and its Origins in L. Van Beethoven's Works // Questions of Interrelation of Mastery, Pedagogy, Theory and Practice. 2015. R. 45, pp. 196-208.

[7] L. Tunbridge, The Song Cycle. Cambridge: Cambridge University Press, 2010. (Cambridge Introductions of Music). 256 p.

[8] Ruth O.Bingham, The Early Nineteenth-Century Song Cycle // The Cambridge Companion to the Lied / ed. by J. Parsons. Cambridge: Cambridge University Press, 2004, pp. 101-119.

[9] L. E. Peake, The Song Cycle: A Preliminary Inquiry into the Beginnings of the Romantic Song Cycle and the Nature of an Art Form. Ph. D. Columbia University, 1968, $336 \mathrm{p}$.

[10] C. Kimball, Art Song: Linking Poetry and Music. Hal Leonard Corporation, USA, 2013 [Electronic resource]. URL: https://books.google.ru/books?id=BcsXAAAAQBAJ\&pg=RA2PA20-IA5\&lpg=RA2-PA20-

IA $5 \& d q=$ The + advent + of + YouTube + allows + us + to + watch + singers, + a nd+often+not+listen+to+them\%E2\%80\%9D.\&source=bl\&ots=Tpbdd VvQiP\&sig=QJSURKYbkFpJd8iw3eHRxYbhbuM\&hl=ru\&sa=X\&v ed=0ahUKEwifr8GI9trZAhVsdt8KHZaEB6oQ6AEIJzAA\#v=onepag e\&q $=$ The $\% 20$ advent $\% 20$ of $\% 20$ YouTube $\% 20$ allows $\% 20$ us $\% 20$ to $\% 2$ 0watch $\% 20$ singers $\% 2$ C $\% 20$ and $\% 20$ often $\% 20$ not $\% 20$ listen $\% 20$ to $\% 2$ 0them $\%$ E2\%80\%9D.\&f=false

[11] The Romantic Song Cycle as Literary Genre, Word and Music Studies Defining the Field: Proceeding of the First International Conference on Word and Music Studies at Graz, 1997 / ed. by W. Bernhart and W. Wolf in collaboration with D. Mosley. Rodopy, Amsterdam-Atlanta, Ga 1999.
[12] C. Fox, From Schubert to Sinatra: Why the Song Cycle Speaks to the Heart. [Electronic resource]. URL https://www.theguardian.com/music/2016/oct/07/from-schubert-tosinatra-why-the-song-cycle-speaks-to-the-heart.I. S. Jacobs and C. P. Bean, "Fine particles, thin films and exchange anisotropy," in Magnetism, vol. III, G. T. Rado and H. Suhl, Eds. New York: Academic, 1963, pp. 271-350.

[13] K. Gingerich, The Journey of the Song Cycle: From "The Iliad" to "American Idiot". "Musical Offerings: Vol. 1 : No. 2, Article 3, 2010.

[14] S. C. Walls, An Opera Star's Song Cycle Conjures a Black Man's Life in America. The New York Times, Feb. 16, 2018. [Electronic resource]. https://www.nytimes.com/2018/02/16/arts/music/tyshawn-soreylawrence-brownlee.html

[15] C. Kimball, Art Song: Linking Poetry and Music. 